\title{
Baseline inflammatory markers and disease activity indices predict tapering of biologic agents in ankylosing spondylitis
}

\author{
Marius Trandafir ${ }^{1,2}$, Claudiu C. Popescu ${ }^{2,3}$, Florian Berghea ${ }^{1,2}$, Violeta Bojinca $^{1,2}$, \\ Denisa Predeteanu ${ }^{1,2}$, Ruxandra Ionescu ${ }^{1,2}$ \\ 1"Sf. Maria" Clinical Hospital, Bucharest, Romania \\ 2"Carol Davila" University of Medicine and Pharmacy, Bucharest, Romania \\ 3"Dr. Ion Stoia" Clinical Center for Rheumatic Diseases, Bucharest, Romania
}

\begin{abstract}
Rationale. Clinicians need to have evidence-based information regarding the feasibility of tapering biologics in ankylosing spondylitis (AS).

Objective. The study aims to identify significant predictors of tapering in clinical practice.

Methods and results. AS patients on their first tumor necrosis factor alpha inhibitor (iTNFa) were enrolled between 2015-2017 and followed until the end of the observation or until tapering or switch of their iTNFa. Binary logistic regression was used to predict tapering ("0" for "non-tapering", meaning switches and original posology; "1" for "tapering"), significant if p $<0.05$. Of the 120 included patients, $50.8 \%$ had adalimumab, $21.7 \%$ etanercept, $4.2 \%$ golimumab and $23.3 \%$ infliximab. During follow-up, $40.8 \%$ tapered their initial iTNFa, $40.8 \%$ remained on its original posology, $16.7 \%$ switched it and $1.7 \%$ were lost. Judging by odds ratios (OR), inflammatory markers (e.g. odds ratio ORCRP $=0.936, p=0.014$ ) and activity scores (ORBASDAI $=0.565, p=0.005$ ) significantly reduced the chance for tapering. Compared to patients on the original posology, patients on tapering had a significantly lower prevalence of uveitis ever (6.8\% compared to $11.0 \%, p=0.008$, post-hoc $X^{2}$ test).

Discussion. In a real life setting, no more than half of AS patients treated with TNFa inhibitors can undergo tapering. High baseline inflammatory markers and disease activity indices significantly lower the chance of tapering. From a therapeutic point of view, a non-responsive disease phenotype of AS can be hypothesized and it includes extra-spinal manifestations such as uveitis.
\end{abstract}

Keywords: ankylosing spondylitis; TNF inhibitors; tapering

\section{ABBREVIATIONS}

ANOVA - analysis of variance

AS - ankylosing spondylitis

ASDAS - Ankylosing Spondylitis Disease Activity Score

BASDAI - Bath Ankylosing Spondylitis Activity Index

BASFI - Bath Ankylosing Spondylitis Functional Index

BMI - body mass index

CI - confidence interval

CRP - C-reactive protein

df - degrees of freedom
ESR - erythrocyte sedimentation rate

FBG - fibrinogen

HLA - human leukocyte antigen

IBD - inflammatory bowel disease

iTNF $\alpha$ - inhibitor of TNF $\alpha$

NSAIDs - non-steroidal anti-inflammatory drugs

OR - odds ratio

$\mathbf{T N F} \boldsymbol{\alpha}$ - tumor necrosis factor alpha

\section{INTRODUCTION}

Ankylosing spondylitis (AS) is a chronic inflammatory disease characterized clinically by inflammatory back pain (1) and pathologically by sacroiliac arthritis and formation of syndesmophytes. The pain and, ultimately, the loss of spinal mobility severely alter the quality of life and generate signifi- cant healthcare costs. Pharmacological treatment strategies target different molecules involved in the pathogenesis of AS: cyclooxygenases (non-steroidal anti-inflammatory drugs - NSAIDs), tumor necrosis factor alpha (TNFo; adalimumab, certolizumab, etanercept golimumab, infliximab), interleukin 17 (secukinumab) and miscellaneous (local glucocorticoids and sulfasalazine for peripheral manifesta- 
tions). All these biologic agents, either original or biosimilar, are approved and reimbursed in Romania for use in AS patients. Due to costs, the use of these biologics is restricted to patients who fulfill the following six criteria: diagnosis of AS according to the modified New York criteria (2); Bath Ankylosing Spondylitis Activity Index (BASDAI) (3) $>6$ on two occasions at least 4 weeks apart; Ankylosing Spondylitis Disease Activity Score (ASDAS) (4) $\geq 2.5$; erythrocyte sedimentation rate $(\mathrm{ESR})>28 \mathrm{~mm} / \mathrm{h}$ and/or C-reactive protein (CRP) more than 3 times the upper limit of normal; failure of traditional therapies (NSAIDs, glucocorticoids, sulfasalazine); the lack of contraindications according to summaries of product characteristics.

Since biologics entail high costs and certain risks for the patient (e.g. infections, although there is meta-analytical data that suggest otherwise) (5), neoplasia) (6), the current strategy is to reduce the exposure if the therapeutic benefit is maintained (sustained remission) $(7,8)$, either by reducing the dose per administration or by reducing the time interval between administrations. Clinical research has addressed this issue and it has proven that the doses of biologics can be safely reduced and if the disease flares, the initial posology can be re-administered or the agent can be switched (9-12), both in controlled studies and in real life $(13,14)$. Tapering of biologics is therefore a direct marker of therapeutic success in terms of low disease activity and remission. Since the eventuality of tapering should be discussed with the patient and agreed upon, clinicians need to have evidence-based information regarding the feasibility of this strategy for a specific case. Following this direction, the study aims to identify significant predictors of tapering, factors which either announce or limit the possibility of tapering in clinical practice.

\section{METHODS}

\section{Patients}

All the patients who were evaluated in the day care service of our Rheumatology Department in the random order of presentation between May 2015 and May 2017 were screened for inclusion in the study.

The inclusion criteria included: diagnosis of AS according to the modified New York criteria (2); treatment with a TNF $\alpha$ inhibitor (adalimumab, certolizumab, etanercept, golimumab or infliximab) prescribed by the attending rheumatologist as per drug label and national regulations (at the start of the observation period secukinumab was not yet available for Romanian patients, therefore it was excluded from the data collection).

The following exclusion criteria were applied: age under 18 years; patients with psoriatic arthritis; patients receiving other/investigational biologic agents. Each patient gave written informed consent for the use of clinical data on the occasion of each day care visit and the study was approved by the local ethics committee.

\section{Variables}

For each patient who came to the clinic within the inclusion timeframe (between May 2015 and May 2017), two moments were recorded: the start of the first TNF $\alpha$ inhibitor (which either predated, coincided with the first visit within the timeframe or happened during follow-up) and the endpoint of this treatment (switch before inclusion, switch during follow-up, original posology during the entire observation period, tapering before inclusion or tapering during follow-up). The first time the patient came to the clinic within the time frame, the investigators recorded from the observation sheets and the hospital's electronic clinical data system demographics, disease phenotype characteristics, treatment types, inflammatory markers and disease activity scores.

Demographic data include age, gender, body mass index (BMI; calculated by dividing weight in kilograms by square height in meters, with a cutoff of $30 \mathrm{~kg} / \mathrm{m}^{2}$ for obesity), urban or rural dwelling, level of education.

The disease phenotype was characterized by genetic predisposition (the presence of HLA-B27), disease duration (the time between diagnosis and study inclusion), the presence of extra-spinal (coxitis, peripheral arthritis) and extra-articular manifestations (uveitis, inflammatory bowel disease and psoriasis), which were noted if they were present at the moment of inclusion in the study or anytime during the medical history, as documented by medical doctors (rheumatologist, ophthalmologist, dermatologist, gastroenterologist).

AS diseases activity was evaluated by dosing acute phase reactants (ESR - normal $<20 \mathrm{~mm} / \mathrm{h}$, Westergren method; CRP - normal $<5 \mathrm{mg} / \mathrm{L}$, nephelometry; fibrinogen - normal $<490 \mathrm{mg} / \mathrm{dL}$, enzyme-linked immunoabsorbant assay) and by calcu- 
lation composite indices, such as BASDAI (3), Bath Ankylosing Spondylitis Functional Index (BASFI) $(15,16), \operatorname{ASDAS}_{\mathrm{CRP}}(4,17)$. Data regarding types of treatment (NSAIDs, sulfasalazine, TNF $\alpha$ inhibitors) was also recorded. Both inflammatory markers and disease scores were recorded at the time of inclusion in the study (the first visit within the timeframe).

\section{Statistics}

Normally distributed continuous variables were reported as "mean \pm standard deviation", non-normally distributed continuous variables were reported as "median (minimum-maximum)", while qualitative variables were expressed as "absolute value (percentage of total)". Distribution normality was assessed using descriptive statistics, normality, stemand-leaf plots and the Lillefors corrected Kolmogorov-Smirnov test.

The comparison of continuous variables (e.g. ESR) among the subgroups of treatment endpoint (tapering, switch, and original posology) was assessed using the Kruskal-Wallis $\mathrm{H}$ test, with posthoc analysis using one-way ANOVA and least significant difference analysis. The prevalence of uveitis among subgroups of treatment endpoint was evaluated using the $\chi^{2}$ test, with post-hoc analysis of adjusted residuals.

In order to predict the outcome of tapering, binary logistic regression was used: the dependent binary variable was coded as " 0 " for "non-tapering" (switches and original posology) and " 1 " for tapering, with all models including age (years), dwelling ("0" for "rural" and " 1 " for "urban"), BMI $\left(\mathrm{kg} / \mathrm{m}^{2}\right)$, sex ("0" for "female" and "1" for "male"), inflammatory markers and activity indices.

All tests were considered significant if $p<0.05$ and were done using IBM SPSS v.20 (IBM Inc., Armonk, New York, 2010) for Windows.

\section{RESULTS}

\section{General characteristics}

A total of 120 patients met the inclusion criteria. Table 1 resumes the main demographic and disease-specific variables.

\section{Initial biologic agent}

More than half of the sample was treated with adalimumab as a first choice biologic agent, followed by infliximab, etanercept and golimumab (Fig. 1).

From the first biologic agent, equal fractions of patients $(40.8 \%)$ were either tapered or maintained on the original posology, the rest being either switched on another biologic molecule $(16.7 \%)$ or lost to follow-up (1.7\%; Fig. 2). Tapering was implemented by shared patient-doctor decision in the presence of persistent remission (defined as ASDAS $\leq 1.3$ and normal ESR and CRP values at two successive evaluations at least 6 months apart). Aside from a TNF $\alpha$ inhibition period bellow 2 years, which did not allow attaining persistent remission from a time perspective, attending physicians motivated maintaining their AS patients on the original posology with the following reasons: long disease duration and aggressive disease course; the persistence of ex-

TABLE 1. General characteristics of the sample $(n=120)$

\begin{tabular}{|c|c|c|c|}
\hline age $(\mathrm{y})$ & $44.5 \pm 11.6$ & BASFI & $2.0(0-9)$ \\
\hline male gender & $103(85.8 \%)$ & ASDAS $_{\text {CRP }}$ & $1.30(0.64-5.54)$ \\
\hline BMI $\left(\mathrm{kg} / \mathrm{m}^{2}\right)$ & $25.2 \pm 2.7$ & disease dura on $(\mathrm{y})$ & $12.1 \pm 8.4$ \\
\hline obesity & $5(4.2 \%)$ & peripheral arthri s & $57(47.5 \%)$ \\
\hline urban dwelling & $88(73.3 \%)$ & coxi s & $8(6.7 \%)$ \\
\hline higher educa on & $9(7.5 \%)$ & uvei s & $32(26.7 \%)$ \\
\hline ESR $(\mathrm{mm} / \mathrm{h})$ & $23 \pm 14$ & IBD & $4(3.3 \%)$ \\
\hline CRP $(\mathrm{mg} / \mathrm{L})$ & $4.28(0.4-142)$ & psoriasis & $0(0.0 \%)$ \\
\hline FBG $(\mathrm{mg} / \mathrm{dL})$ & $387(45-789)$ & NSAIDs & $118(98.3 \%)$ \\
\hline BASDAl & $1.0(0-9.0)$ & sulfasalazine & $59(49.2 \%)$ \\
\hline
\end{tabular}

Note: variables are reported as: "mean \pm standard deviation" for continuous normal

distribution; "median (minimum-maximum)" for continuous non-normal distribution; "absolute value (fraction of total)" for nominal variables.

Abbreviations: ASDAS $_{\text {CRP }}=$ Ankylosing Spondylitis Disease Activity Score using CRP; BASDAI = Bath Ankylosing Spondylitis Disease Activity Index; BASFI = Bath Ankylosing Spondylitis Functional Index; BMI = body mass index; $C R P$ = C-reactive protein; $E S R$ = erythrocyte sedimentation rate; FBG = fibrinogen; HLA = human leukocyte antigen; $\mathrm{IBD}=$ inflammatory bowel disease; NSAIDs = non-steroidal anti-inflammatory drugs; $y=$ years. 


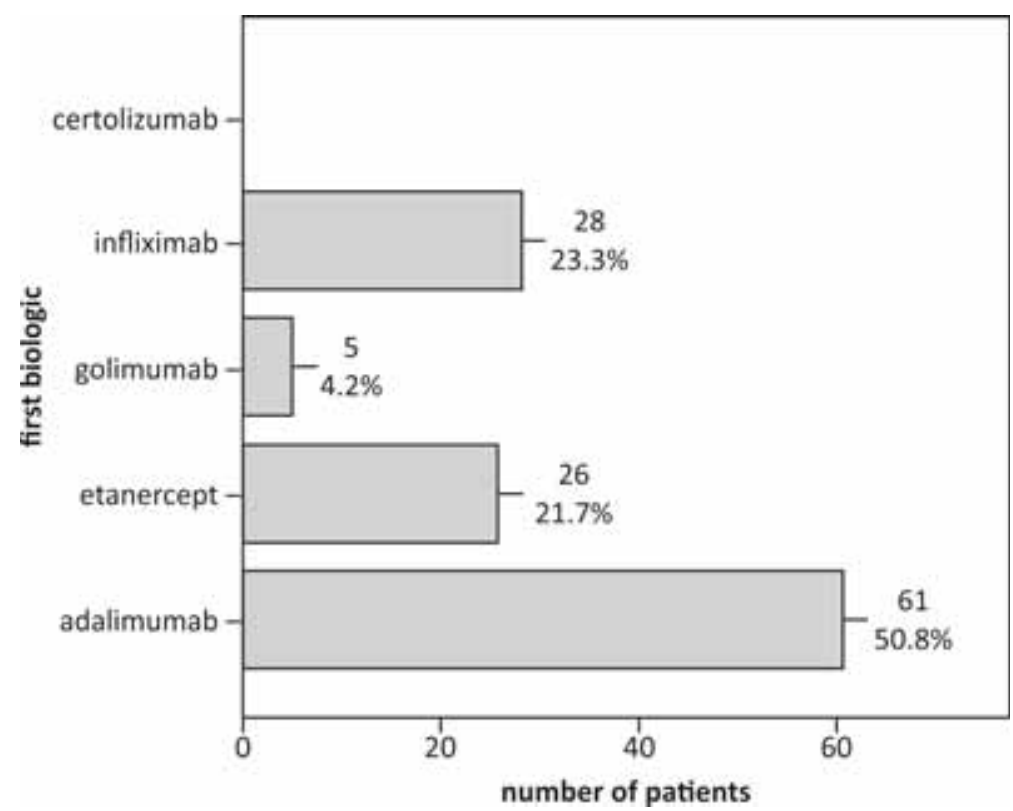

FIGURE 1. The distribution of the first biologic molecules $(n=120)$

tra-articular manifestations (e.g. uveitis); shared decision based on patient's choice.

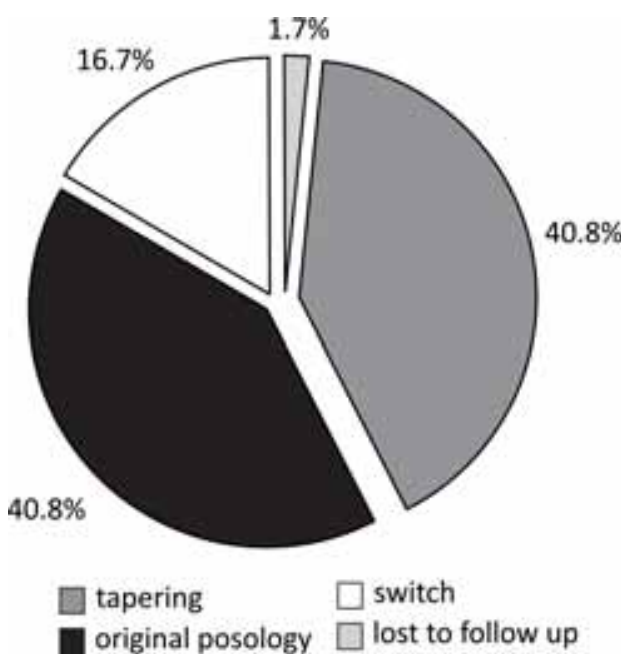

FIGURE 2. End-point of initial biologic agent $(n=120)$.

The causes of switch included: 5 primary non-responders (25\%), 12 secondary non-responders $(60 \%), 2$ cases of uveitis onset during biologic therapy $(10 \%)$ and 1 case of inflammatory bowel disease onset during biologic therapy $(5 \%)$. Of note, there were no cases which stopped biologic treatment altogether during follow-up.

After the exclusion of the two cases lost to follow-up $(\mathrm{n}=2)$, the sample was divided according to the endpoint of their first biologic agent, respectively tapering $(n=49)$, original posology $(n=49)$ and switch $(n=20)$. Comparing these three subgroups, significant over-all differences were observed in terms of inflammatory markers and disease activity scores. Post-hoc analysis revealed that these differences were generated by comparing the "tapering" subgroup with "original posology" subgroup and respectively comparing "tapering" to "switch" (Table 2).

TABLE 2. Comparison of inflammatory makers and disease activity scores between the endpoint subgroups of the first biologic therapy $(n=118)$

\begin{tabular}{|l|c|c|c|c|}
\hline & $\begin{array}{c}\text { tapering } \\
(n=49)\end{array}$ & $\begin{array}{c}\text { original } \\
\text { posology } \\
(n=49)\end{array}$ & $\begin{array}{c}\text { switch } \\
(n=20)\end{array}$ & $\mathbf{p}$ \\
\hline$E S R(\mathrm{~mm} / \mathrm{h})$ & $11(11)$ & $17(29)^{*}$ & $18(31)^{*}$ & 0.023 \\
\hline$F B G(\mathrm{mg} / \mathrm{dL})$ & $324(101)$ & $400(154)^{\#}$ & $400(217)^{\#}$ & 0.001 \\
\hline$C R P(\mathrm{mg} / \mathrm{L})$ & $3.3(4.6)$ & $6.8(17.3)^{\&}$ & $10.5(50.9)^{\&}$ & 0.048 \\
\hline$B A S D A I$ & $0.80(0.80)$ & $1.15(2.00)^{\S}$ & $2.10(2.50)^{\S}$ & 0.022 \\
\hline$B A S F I$ & $1.1(1.0)$ & $2.2(2.8)^{ף}$ & $3.1(1.7)^{\natural}$ & $<0.001$ \\
\hline$A S D A S_{C R P}$ & $1.20(0.46)$ & $1.30(1.83)^{\ddagger}$ & $1.71(1.16)^{\ddagger}$ & 0.005 \\
\hline
\end{tabular}

Notes: the 2 patients lost to follow-up were excluded from the analysis ( $n=118$ ); variables are reported as "median (interquartile range)"; $p$ values represent the significance of Kruskal-Wallis $\mathrm{H}$ tests; significant differences among between "tapering" and the other two categories, identified by one-way ANOVA analysis with post-hoc Fisher's LSD tests, are marked with special characters: * ESR "tapering" versus "original posology" $\mathrm{p}=0.008$; * ESR "tapering" versus "switch" = 0.009; \# FBG "tapering" versus "original posology" $p=0.001$; \# FBG "tapering" versus "switch" $p=0.001 ; \&$ CRP "tapering" versus "original posology" $p=$ 0.018; \# CRP "tapering" versus "switch" $p<0.001$; § BASDAI "tapering" versus "original posology" $p=0.001$; $\S$ BASDAl "tapering" versus "switch" $p=0.025$; ๆ BASFI "tapering" versus "original posology" $p<$ 0.001; ๆ BASFI "tapering" versus "switch" $p=0.001 ; \ddagger$ ASDAS $_{\text {CRP "taper- }}$ ing" versus "original posology" $p=0.001 ; \ddagger$ ASDAS $_{\text {CRP }}$ "tapering" versus "switch" $\mathrm{p}=0.002$. Abbreviations: ASDAS $_{\mathrm{CRP}}=$ Ankylosing Spondylitis Disease Activity Score using CRP; BASDAI = Bath Ankylosing Spondylitis Disease Activity Index; BASFI = Bath Ankylosing Spondylitis Functional Index; CRP = C-reactive protein; ESR = erythrocyte sedimentation rate; $F B G$ = fibrinogen; LSD = Least Significant Difference. 


\section{Prediction of tapering}

Since the inflammatory markers and activity indices produced significant differences among treatment endpoint subgroups, they were included in logistic regression models in order to predict tapering (Table 3), yielding significant results: both inflammatory markers and AS activity indices significantly reduce the chance of tapering the first biologic agent.

TABLE 3. Binary logistic regression models for tapering

\begin{tabular}{|l|c|c|c|}
\hline & $\boldsymbol{O R}$ & $\boldsymbol{P}$ & $\mathbf{9 5 \%} \mathbf{C l}$ \\
\hline ESR $^{*}$ & 0.962 & 0.004 & $0.938-0.988$ \\
\hline FBG $^{\#}$ & 0.992 & 0.001 & $0.988-0.997$ \\
\hline CRP $^{8}$ & 0.936 & 0.014 & $0.887-0.986$ \\
\hline BASDAI $^{5}$ & 0.565 & 0.005 & $0.377-0.845$ \\
\hline BASFI $^{\text {q }}$ & 0.399 & $<0.001$ & $0.253-0.627$ \\
\hline ASDAS $_{\text {CRP }}{ }^{\ddagger}$ & 0.335 & 0.003 & $0.165-0.683$ \\
\hline
\end{tabular}

Notes: the dependent binary variable was coded as " 0 " for "non-tapering" (switches and original posology) and " 1 " for tapering; all models included age (years), dwelling (" 0 " for "rural" and " 1 " for "urban"), BMI $\left(\mathrm{kg} / \mathrm{m}^{2}\right)$, sex (" 0 " for "female" and " 1 " for "male") and each one of the above variables; ${ }^{*}-\chi^{2}=15.6 ; p=0.008 ; d f=5 ; R^{2}=0.164 ; \#-\chi^{2}=18.8$; $p=0.002 ; d f=5 ; R^{2}=0.196 ; \&-\chi^{2}=18.7 ; p=0.002 ; d f=5 ; R^{2}=0.195 ; \S$ $-\chi^{2}=17.6 ; p=0.004 ; d f=5 ; R^{2}=0.184 ; \uparrow-\chi^{2}=32.6 ; p<0.001 ; d f=5 ; R^{2}$ $=0.324 ; \ddagger-\chi^{2}=21.2 ; p=0.001 ; d f=5 ; R^{2}=0.219$.

Abbreviations: ASDAS $_{\mathrm{CRP}}=$ Ankylosing Spondylitis Disease Activity Score using CRP; BASDAI = Bath Ankylosing Spondylitis Disease Activity Index; $\mathrm{BASFI}=$ Bath Ankylosing Spondylitis Functional Index; $\mathrm{BMI}=$ body mass index; $\mathrm{Cl}=$ confidence interval; $\mathrm{CRP}=\mathrm{C}$-reactive protein; $\mathrm{df}=$ degrees of freedom; $E S R=$ erythrocyte sedimentation rate; $F B G=$ fibrinogen; $\mathrm{OR}=$ odds ratio.

The causes of switching the first biologic agent were studied in terms of differences among treatment endpoint subgroups. The prevalence of uveitis was significantly lower in the tapering subgroup compared to the original posology subgroup (Fig. 3).

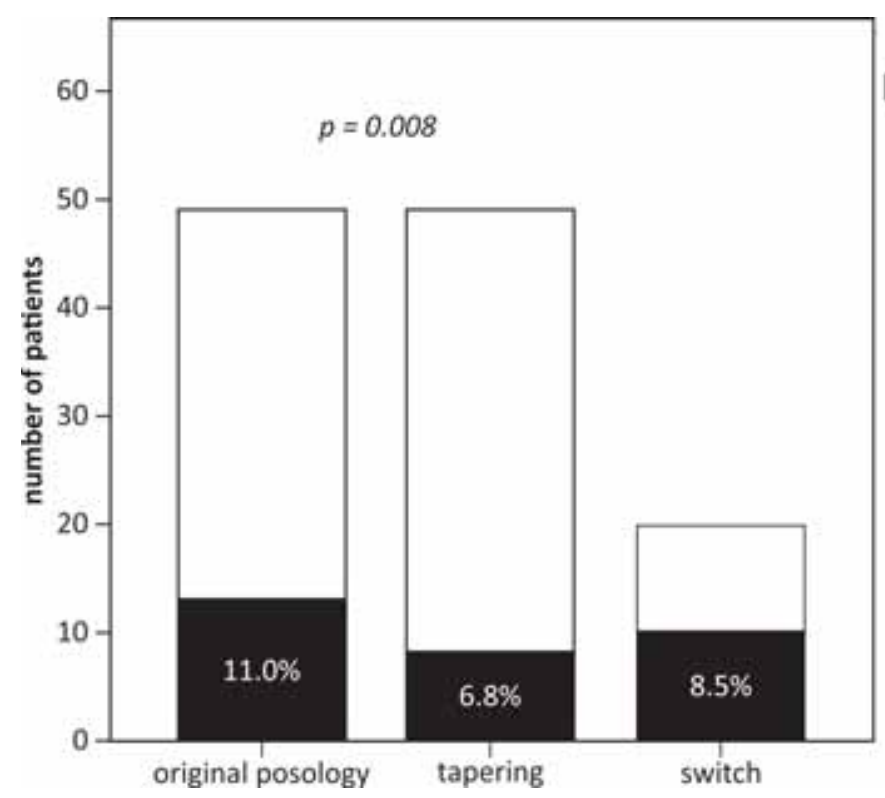

\section{DISCUSSION}

Summarizing our results, we observed that $40.8 \%$ of our patients tapered their initial biologic agent (none of our patients discontinued treatment altogether) and that baseline inflammatory markers and disease activity indices significantly predict tapering. To our knowledge, the published peer-review literature did not address directly the issue of tapering prediction yet.

The predictive value of inflammatory markers and activity indices has been investigate though, and prospective clinical trial have reported that baseline CRP in AS predicts radiographic progression (18) and it also predicts the retention rate of TNF $\alpha$ inhibitors (19). CRP is therefore a marker of disease severity of AS, just as it is in rheumatoid arthritis (20), and if it is elevated at baseline one would expect a more severe disease phenotype which would be less likely to respond to biologics sufficiently in order to gain sustained remission and tapering. This hypothesis was proved: CRP and activity scores (BASDAI, ASDAS) are independent predictors of response, continuation and discontinuation of TNF $\alpha$ inhibitors in AS (21). Our results come as a natural continuation of these observations: if baseline acute phase reactants and activity scores predict the magnitude of response and the treatment duration, they should also have an influence on the possibility of therapeutic tapering, which we have observed. In our opinion, further studies into the matter should target a prediction model for tapering which would include baseline inflammatory markers and disease activity
FIGURE 3. The prevalence of uveitis among patients on tapering, original posology and switch $(p=0.016$ for overall comparison using $X^{2}$ test; $p=0.008$ for the post-hoc comparison between tapering and original posology using adjusted residuals analysis) 
indices, but also relevant cut-off points, for which our study was not adequately sized and statistically powered. This information is highly relevant for the long term management of AS, since approximately $50 \%$ of AS patients on tapered doses of biologics maintain their clinical benefit over the given observational periods (22-24), which means that the other tapered half flares and needs either re-administration of the initial regime or switch to another molecule type or mode of action. On one hand, the fact that only half of a cohort of AS on biologics can be tapered speaks of the overall success of these drugs, which is a breakthrough compared to conventional therapy, but only a first step compared to the clinical reality of the disease. On the other hand, the failure to control disease activity enough to allow tapering reveals a fundamental flaw in the purpose of the medication, namely suppression of inflammation, which is quantified by measurable inflammatory markers (e.g. CRP). Since the production of CRP is an expression of the pro-inflammatory cytokines, it seems that either TNF $\alpha$ is not that important to the pathogenesis of AS or the pathogenic process bypasses TNF $\alpha$ inhibition, a hypothesis suited for fundamental research.

We also observed a significantly higher prevalence of uveitis among AS patients who were maintained on their original TNF $\alpha$ inhibitor posology compared to patients who tapered their TNF $\alpha$ inhibitor. Experience has showed that $\mathrm{TNF} \alpha$ inhibitors
(25), especially adalimumab and infliximab (26), decrease the rate of uveitis in AS patients. In clinical practice, the presence of uveitis can influence the choice of the first TNF $\alpha$ inhibitor and it can also be a reason for switch if it appears during the treatment with a specific TNF $\alpha$ inhibitor. In either case, from a therapeutic point of view uveitis seems to be a maker of a more severe disease phenotype (associated with other severe manifestations like coxitis and peripheral arthritis (27)), which therefore has a lower chance to be adequately controlled by biologics and subsequently a lower chance to undergo treatment tapering.

In spite of the significant observations, our study has certain limitations which can influence the relevance of the results: the retrospective design, the relatively small sample size, the national regulations which impose specific selection criteria of eligibility for biologic therapy.

\section{CONCLUSION}

In a real life setting, no more than half of AS patients treated with TNF $\alpha$ inhibitors can undergo tapering. High baseline inflammatory markers and disease activity indices significantly lower the chance of tapering. From a therapeutic point of view, a non-responsive disease phenotype of AS can be hypothesized and it includes extra-spinal manifestations such as uveitis.

Conflict of interest: none declared Financial support: none declared

\section{REFERENCES}

1. Sieper J., van der Heijde D., Landewe R., Brandt J., Burgos-Vagas R., Collantes-Estevez E., et al. New criteria for inflammatory back pain in patients with chronic back pain: a real patient exercise by experts from the Assessment of SpondyloArthritis international Society (ASAS). Ann Rheum Dis 2009, 68(6):784-788.

2. van der Linden S., Valkenburg H.A., Cats A. Evaluation of diagnostic criteria for ankylosing spondylitis. A proposal for modification of the New York criteria. Arthritis Rheum 1984, 27(4):361-368.

3. Garrett S., Jenkinson T., Kennedy L.G., Whitelock H., Gaisford P., Calin A. A new approach to defining disease status in ankylosing spondylitis: the Bath Ankylosing Spondylitis Disease Activity Index. J Rheumatol 1994, 21(12):2286-2291.

4. Lukas C., Landewe R., Sieper J., Dougados M., Davis J., Braun J., van der Linden S., van der Heijde D. Assessment of SpondyloArthritis international S: Development of an ASASendorsed disease activity score (ASDAS) in patients with ankylosing spondylitis. Ann Rheum Dis 2009, 68(1):18-24.

5. Wang S., He Q., Shuai Z. Risk of serious infections in biological treatment of patients with ankylosing spondylitis and nonradiographic axial spondyloarthritis: a meta-analysis. Clin Rheumatol 2018, 37(2):439-450.

6. Chuiwn D., Wenli L., Yunyun F., Yongzhe L., Fengchun Z. Risk of malignancy in ankylosing spondylitis: a systematic review and meta-analysis. Sci Rep 2016, 6: 32063.

7. Braun J., van den Berg R., Baraliakos X., Boehm H., BurgosVargas R., Collantes-Estevez E., Dagfinrud H., Dijkmans B., Dougados M., Emery P. et al. 2010 update of the ASAS/EULAR recommendations for the management of ankylosing spondylitis. Ann Rheum Dis 2011, 70(6):896-904.

8. Van der Heijde D., Ramiro S., Landewe R., Baraliakos X., Van den Bosch F., Sepriano A., Regel A., Ciurea A., Dagfinrud H., Dougados M. et al. 2016 update of the ASAS-EULAR management recommendations for axial spondyloarthritis. Ann Rheum Dis 2017, 76(6):978-991.

9. Li J., Wang X., Han Z., Zhang Y., Wang Y., Zhang Y., Li W. Dose reduction of recombinant human tumor necrosis factor inhibitors (etanercept) can be effective in ankylosing spondylitis patients with synovitis of the hip in a Chinese population. Int J Immunopathol Pharmacol 2016, 29(3):510-515

10. Steel L., Gaffney K. Maintenance of Low Disease Activity following Tumor Necrosis Factor Inhibitor Dose Tapering in Ankylosing Spondylitis. J Rheumatol 2017, 44(8):1292.

11. Morck B., Pullerits R., Geijer M., Bremell T., Forsblad-d'Elia H. Infliximab dose reduction sustains the clinical treatment effect in 
active HLAB27 positive ankylosing spondylitis: a two-year pilot study. Mediators Inflamm 2013, 2013:289845.

12. Cantini F., Niccoli L., Cassara E., Kaloudi O., Nannini C. Duration of remission after halving of the etanercept dose in patients with ankylosing spondylitis: a randomized, prospective, long-term, follow-up study. Biologics 2013, 7:1-6.

13. Fong W., Holroyd C., Davidson B., Armstrong R., Harvey N., Dennison E., Cooper C., Edwards C.J. The effectiveness of a real life dose reduction strategy for tumour necrosis factor inhibitors in ankylosing spondylitis and psoriatic arthritis. Rheumatology (Oxford) 2016, 55(10):1837-1842.

14. Baraliakos X., Heldmann F., van den Bosch F., Burmester G., Gaston H., van der Horst-Bruinsma I.E., Krause A., Schmidt R., Schneider M., Sieper J. et al. Long-term efficiency of infliximab in patients with ankylosing spondylitis: real life data confirm the potential for dose reduction. RMD Open 2016, 2(2):e000272.

15. Calin A., Garrett S., Whitelock H., Kennedy L.G., O'Hea J., Mallorie P., Jenkinson T. A new approach to defining functional ability in ankylosing spondylitis: the development of the Bath Ankylosing Spondylitis Functional Index. J Rheumatol 1994, 21(12):2281-2285.

16. Udrea G., Ciobanu C., Mihai C., Stoica V., Suteanu S., van der Heijde D., van der Linden S. Evaluation of a Romanian version of the Bath Ankylosing Spondylitis Functional Index (BASFI) in patients with spondylarthropathies. Rom J Intern Med 2004, 42(1):199-209.

17. Popescu C., Trandafir M., Badica A., Morar F., Predeteanu D. Ankylosing spondylitis functional and activity indices in clinical practice. J Med Life 2014, 7(1):78-83.

18. Braun J., Baraliakos X., Hermann K.G., Xu S., Hsu B. Serum C-reactive Protein Levels Demonstrate Predictive Value for Radiographic and Magnetic Resonance Imaging Outcomes in Patients with Active Ankylosing Spondylitis Treated with Golimumab. J Rheumatol 2016, 43(9):1704-1712.

19. Luc M., Gossec L., Ruyssen-Witrand A., Salliot C., Duclos M., Guignard S., Dougados M. C-reactive protein predicts tumor necrosis factor-alpha blocker retention rate in axial ankylosing spondylitis. J Rheumatol 2007, 34(10):2078-2081.
20. Poole C.D., Conway P., Reynolds A., Currie C.J. The association between $\mathrm{C}$-reactive protein and the likelihood of progression to joint replacement in people with rheumatoid arthritis: a retrospective observational study. BMC Musculoskelet Disord 2008, 9:146.

21. Arends S., Brouwer E., van der Veer E., Groen H., Leijsma M.K., Houtman P.M., Th AJTL, Kallenberg C.G., Spoorenberg A. Baseline predictors of response and discontinuation of tumor necrosis factor-alpha blocking therapy in ankylosing spondylitis: a prospective longitudinal observational cohort study. Arthritis Res Ther 2011, 13(3):R94.

22. Chen M.H., Lee M.H., Liao H.T., Chen W.S., Lai C.C., Tsai C.Y. Health-related quality of life outcomes in patients with rheumatoid arthritis and ankylosing spondylitis after tapering biologic treatment. Clin Rheumatol 2018, 37(2):429-438.

23. Park J.W., Kwon H.M., Park J.K., Choi J.Y., Lee E.B., Song Y.W., Lee E.Y. Impact of Dose Tapering of Tumor Necrosis Factor Inhibitor on Radiographic Progression in Ankylosing Spondylitis. PLoS One 2016, 11(12):e0168958.

24. Yates M., Hamilton L.E., Elender F., Dean L., Doll H., MacGregor A.J., Thomas J., Gaffney K. Is Etanercept 25 mg Once Weekly as Effective as $50 \mathrm{mg}$ at Maintaining Response in Patients with Ankylosing Spondylitis? A Randomized Control Trial. J Rheumatol 2015, 42(7):1177-1185.

25. Kim M., Won J.Y., Choi S.Y., Ju J.H., Park Y.H. Anti-TNFalpha Treatment for HLA-B27-Positive Ankylosing Spondylitis-Related Uveitis. Am J Ophthalmol 2016, 170:32-40.

26. Lie E., Lindstrom U., Zverkova-Sandstrom T., Olsen I.C., Forsblad-d'Elia H., Askling J., Kapetanovic M.C., Kristensen L.E., Jacobsson L.T.H. Tumour necrosis factor inhibitor treatment and occurrence of anterior uveitis in ankylosing spondylitis: results from the Swedish biologics register. Ann Rheum Dis 2017, 76(9):1515-1521.

27. Sun L., Wu R., Xue Q., Wang F., Lu P. Risk factors of uveitis in ankylosing spondylitis: An observational study. Medicine (Baltimore) 2016, 95(28):e4233. 